\title{
Cambios en el sistema de residencia, los grupos domésticos y la familia en Lacanjá Chansayab desde la teoría de control cultural
}

\section{Changes in Residence System, Domestic Groups and Family at Lacanja Chansayab from the Theory of Cultural Control}

\author{
Fredy Alfonso Ochoa Fonseca \\ Eduardo Bello Baltazar \\ ERIN Estrada Lugo \\ Carla Zamora Lomelí \\ Gloria Mariel SuÁrez GutiérReZ \\ El Colegio de la Frontera Sur, México
}

\begin{abstract}
Resumen: El sistema de residencia matrilocal de los lacandones de Lacanjá Chansayab, Chiapas, ha sido descrito por varios autores como un elemento cultural fundamental que aún conservan; a él están asociadas la reproducción social de la etnia y la sustentabilidad de la selva lacandona. Mediante la etnografía, esta investigación muestra cómo la forma de organización denominada vejo'ovex, que trasciende el grupo de residencia y combina el grupo doméstico y la familia, ha cambiado hacia la ambilocalidad. El artículo tiene como objetivo discutir las causas e implicaciones de dicho cambio, para lo cual se enmarca en la teoría de control cultural de los elementos materiales asociados al territorio y la casa. Se identifican tres detonantes del cambio, la sedentarización y posterior titulación de tierras en los años setenta, la inmigración de lacandones de otras zonas y la conformación de empresas familiares dedicadas al ecoturismo. Dentro de las conclusiones se encuentra que los elementos territorio, vejo'ovex y trabajo transitan entre cultura apropiada y cultura enajenada, a lo cual se vinculan transformaciones en los conceptos de herencia, propiedad, residencia y familia.
\end{abstract}

Palabras clave: cambios culturales; parentesco; herencia; lacandones; Chiapas.

ABSTRACT: The matrilocal system of residence of the Lacandons of Lacanjá Chansayab, Chiapas, has been described by several authors as a fundamental cultural element 
that is still conserved. This system is associated to the social reproduction of the ethnic group and the sustainability of the Lacandon jungle. This form of organization transcends the residence group and combines the domestic group and the family. Through ethnography, this research shows how this form of organization, called vejo'ovex, has changed towards ambilocality. The article aims to discuss the causes and implications of such change which is framed in the theory of cultural control, focused on the material elements associated with territory and home. Three triggers of change are identified, the sedentary and subsequent land titling in the 70s, the immigration of Lacandons from other areas, and the conformation of family businesses dedicated to ecotourism. Among the conclusions found, the elements: territory, Vejo'ovex and work, transit between appropriated culture to alienated culture, linked with transformations in the concepts of inheritance, property, residence, and family.

KeYwords: Cultural change; kinship; heritage; Lacandon; Chiapas.

RECEPCIÓN: 29 de agosto de 2019.

ACEPTACIÓN: 9 de octubre de 2019.

Dor: https://doi.org/10.19130/iifl.ecm.57.2021.18659

\section{Introducción}

Lacanjá Chansayab se ubica en el municipio de Ocosingo, Chiapas, dentro de la Selva Lacandona (De Vos, 2002), y es una de las cuatro subcomunidades lacandonas junto con Ojo de Agua Chankín, Nahá y Metzabok; de éstas, es la de mayor población, con alrededor de $976^{1}$ habitantes lacandones de los 1200 existentes (Instituto Nacional de los Pueblos Indígenas, ${ }^{2} 2015$ ).

Nos referimos a los lacandones como grupo étnico, en el sentido en que lo define Bonfil Batalla:

Conjunto relativamente estable de individuos que mantiene continuidad histórica porque se reproduce biológicamente y porque sus miembros establecen entre sí vínculos de identidad social distintiva a partir de que se asumen como una unidad política, que tiene derecho exclusivo al control de unos elementos culturales que consideran propios (Bonfil, 1991: 178). ${ }^{3}$

Los lacandones, quienes se llaman a sí mismos hach winik, "gente verdadera" (Boremanse, 1978: I), hablan maya lacandón (Baer y Baer, 2018; Hofling, 2014); se les reconoce por estar adaptados al ambiente del bosque tropical y a las condiciones de la selva (Marion, 1991), al igual que su interés por conservarla debido a que está ligada de forma profunda con su cosmogonía y la selva es su hogar.

${ }^{1}$ Según cifras de la Casa de Salud de la comunidad en 2018.

2 En adelante INPI.

${ }^{3}$ Aunque Bonfil no incluye la lengua en este concepto, para los lacandones sí resulta un elemento clave en su identidad social. 
Con base en sus diferencias culturales, étnicas y linguiísticas, ${ }^{4}$ se les divide en dos grupos: norte y sur (Boremanse, 1998: 7). Los primeros habitaban en un área amplia desde el río Jethá hasta el río Chocolhá, en torno a las lagunas de Nahá, Monte Líbano, Metzabok y Puná (Nečasová, 2010: 82). Por su parte, los lacandones del sur vivían en dos subgrupos, uno en el centro de la Selva Lacandona, en el río Jataté a un costado de la laguna de Miramar, y el otro en la desembocadura del río Lacanjá (Boremanse, 1998: 15). Aunque hay diversas hipótesis sobre su origen, algunos autores consideran que los del norte provienen de la península de Yucatán y los del sur del Petén guatemalteco (Eroza, 2006: 7).

El patrón de asentamiento y residencia de los lacandones no corresponde a la conformación de comunidades o poblados; se trata de núcleos socioparentales distribuidos en la selva, es decir, grupos constituidos por personas vinculadas entre sí mediante lazos de parentesco, cada uno con varias unidades de residencia tipo choza en las que habitan dos o tres generaciones (Eroza, 2006). En el pasado estos grupos estaban alejados varios kilómetros uno del otro, y los contactos entre ellos se limitaban a intercambiar objetos y mujeres (Boremanse, 1978).

Esta forma tradicional de residencia se expresa en las representaciones colectivas de los lacandones; para ellos las cuevas y las grandes rocas situadas alrededor de las ruinas de los mayas antiguos o las que se encuentran cerca del lago Mensabak están habitadas por dioses (Boremanse, 1978: 25; 1998: 27). Dichas rocas tienen la particularidad de que no se encuentran aisladas, sino en grupos, los cuales reflejan el modelo de su sistema de residencia (Boremanse, 1978: 25; 1998: 27). Los dioses viven en grupos socioparentales. Cada una de las rocas y cuevas es habitada por una pareja junto con sus hijos pequeños; en la roca más grande reside el dios superior con su esposa, y cerca, en otras rocas que no están juntas pero sí a la vista, tienen residencia las hijas de este dios con sus esposos (Boremanse, 1978: 25). Es decir, que los dioses habitan en un sistema de residencia matrilocal, ya que los esposos de las hijas viven en el grupo del padre de la esposa.

Cada uno de estos grupos es llamado vejo'ovex en maya lacandón que, como veremos más adelante, quiere decir familia-grupo de residencia y grupo doméstico. Este último es un elemento esencial de su cultura, al que están ligadas su forma de organización y reproducción social, al igual que su sistema económico, las actividades de aprovechamiento y uso de los recursos naturales. La Figura 1 muestra un vejo'ovex actual, con la unidad de residencia de los padres (01), alrededor de la cual, una vez que los hijos o las hijas ${ }^{5}$ se casan, construyen sus unidades de residencia (02, 03 y 04). Puede haber dos o tres generaciones en cada grupo. No se trata de cuadrículas estrictas, ni hay barreras físicas entre ellas. La forma del vejo'ovex es irregular, sus límites están dados por carreteras, ríos, quebradas

\footnotetext{
${ }^{4}$ Hablan dos dialectos del mismo idioma (Boremanse, 1998: 7).

5 Ya sea por matrilocalidad, patrilocalidad o ambilocalidad como se explica en el marco conceptual.
} 
o cercas vivas. En la parte inferior se muestra la genealogía: los padres tuvieron seis hijos y seis hijas, la soltera reside en la misma choza de sus padres (01), tres de los hijos casados viven junto con sus pequeños hijos en chozas alrededor de sus padres (02, 03 y 04); los demás, también casados, cinco hijas (09 al 13) y tres hijos (06 al 08), viven en otros grupos de residencia.

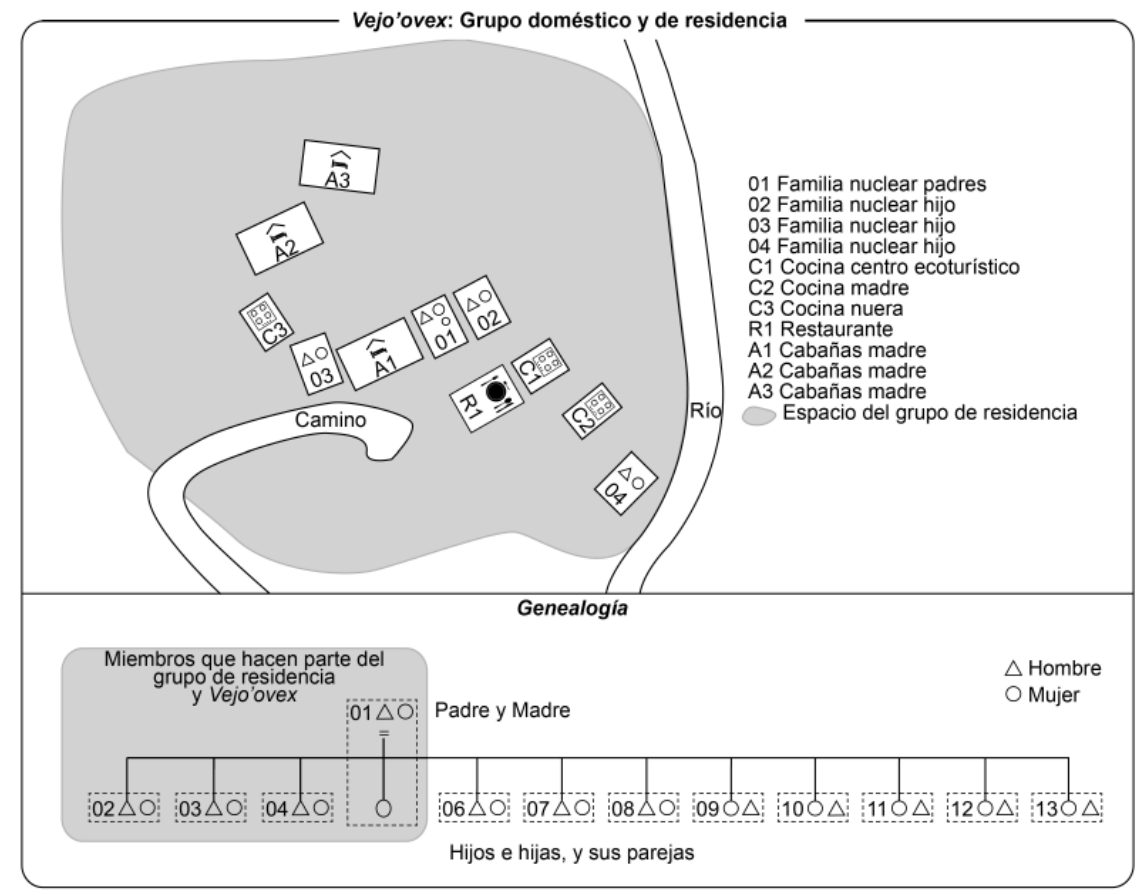

Figura 1. Ejemplo de vejo'ovex (Autoría propia).

El mantenimiento de sus formas de vida sustentable, su agricultura itinerante a través de la milpa, y con ello la selva (Ford y Nigh, 2015: 13-15; Nations y Nigh, 1980), dependían de la disposición de un amplio territorio, así como de un patrón de dispersión a lo largo y ancho de la selva de estos grupos socioparentales (Boremanse, 1978; Eroza, 2006).

Asimismo, ligado al patrón de asentamiento tradicional estaba su forma de autoridad; al no tratarse de una estructura comunitaria, no contaban con un líder. La figura de autoridad le correspondía al hombre mayor de cada grupo socioparental, sustentada en sus conocimientos, así como en su capacidad para agrupar en torno suyo a la mayor cantidad de miembros de la familia, lo que representaba una mayor capacidad productiva y mayor prestigio (Boremanse, 1978; Eroza, 2006).

Es de notar que hasta hace unas décadas era común la práctica de la poligamia entre los lacandones; un hombre podía tener entre dos y cinco mujeres con 
quienes compartía el espacio de residencia. Sin embargo, debido a la llegada de diferentes iglesias cristianas y la consecuente transformación de sus creencias religiosas, hoy esta práctica está casi extinta (Boremanse, 1998; Eroza, 2006; Marion, 1999); en la actualidad, en Lacanjá tan sólo hay dos casos de hombres mayores con dos esposas, aunque ya no comparten el espacio de residencia con ellas, pues cada una vive en un espacio distinto.

Una diferencia de vital importancia es que el sistema de residencia posmarital de los lacandones del norte es ambilocal, ${ }^{6}$ mientras que el de los del sur es matrilocal, aunque con excepciones de ambilocalidad (Boremanse, 1978; 1998). ${ }^{7}$ No obstante, en ambos casos se trata de un tipo de organización socioparental, en la que de forma gradual los hombres construyen el fundamento de su autoridad, y en la cual las relaciones al interior de cada grupo de residencia se vinculan con la producción y distribución de bienes y alimentos (Eroza, 2006), y también con la reproducción de los elementos culturales y sociales que los caracterizan.

Los hach winik contemporáneos ya no viven dispersos en la selva, ni son seminómadas. Desde mediados del siglo xx son sedentarios debido a la migración de campesinos e indígenas provenientes de diversas regiones de Chiapas y otros estados del sur de México y de Guatemala hacia la Selva Lacandona y la posterior titulación de tierras, así como por la necesidad de llevarles el desarrollo, y con ello los servicios de energía y agua, al igual que por la llegada del evangelizador Baer en la década de 1950 (De Vos, 2002; Marion, 1999; Trench, 2002).

A pesar de que para Boremanse (1978) y Marion (1999), con base en el trabajo de campo realizado en los años setenta y noventa respectivamente, el sistema de residencia de los lacandones se había mantenido, en este estudio mostramos cómo en el caso de Lacanjá ha cambiado hacia la ambilocalidad; esta transformación en el núcleo de reproducción social es de vital importancia, por lo que el objetivo a continuación será discutir, en el marco de la teoría de control cultural (Bonfil, 1991), cuáles pueden ser las causas e implicaciones de dicho cambio.

Nos preguntamos si este cambio forma parte de la homogenización del México indígena (Bonfil, 1990). Inicialmente cada pueblo que habitaba lo que hoy es México tenía una identidad social y cultural particular; con la llegada de la Colonia todos pasaron a ser indígenas, la Independencia y la Revolución Mexicana no contribuyeron a reconocer la diversidad, menos aún los movimientos de los años treinta de desindianización. Por el contrario, el indigenismo del siglo xx y la búsqueda de ese México imaginario llevarín a una homogenización mayor del ser indígena, reduciendo el México profundo a algunas prácticas culturales en pequeñas comunidades casi aisladas (Bonfil, 1990).

\footnotetext{
${ }^{6}$ Es decir, no existe una norma fija de residencia posmarital (Fox, 1990).

${ }^{7}$ Boremanse (1998:104) señala que, a comienzos de siglo xx, Tozzer encontró que los lacandones del norte eran patrilocales, situación que había cambiado en los setenta cuando dicho investigador realizaba su tesis.
} 
Tal cuestión nos lleva a discutir si el control sobre los conocimientos y las prácticas asociadas al sistema de residencia lacandón pueden estar transitando hacia una cultura enajenada, impuesta o apropiada (Bonfil, 1991). Al respecto, el control cultural se entiende como

el sistema según el cual se ejerce la capacidad social de decisión sobre los elementos culturales. Los elementos culturales son todos los componentes de una cultura que resulta necesario poner en juego para realizar todas y cada una de las acciones sociales; mantener la vida cotidiana, satisfacer necesidades, definir y solventar problemas, formular y tratar de cumplir aspiraciones (Bonfil, 1991: 171).

El control cultural es dinámico, por lo que requiere ser visto como sistema y como proceso. Verlo como sistema permite diferenciar los ámbitos de la cultura y definir la estructura de las decisiones en determinado momento. Como proceso, esos ámbitos y estructura adquieren movimiento, con lo que se muestran las tensiones, las contradicciones y los conflictos (Bonfil, 1991). En el marco de Bonfil (1991), la cultura apropiada es aquella en la que los elementos culturales ajenos están bajo el control y capacidad de decisión del grupo, elementos que continúan siendo ajenos en tanto el grupo no tiene la capacidad de producirlos por sí mismo, y cuyo uso requiere de la asimilación de conocimientos y habilidades, así como de la modificación o ajuste de algunas pautas de organización social o elementos simbólicos; la cultura enajenada, por su parte, es aquella en la que el grupo ha perdido la capacidad de decisión sobre los elementos culturales propios.

El presente artículo es un estudio cualitativo, a partir de la etnografía, con el enfoque de Ingold (2017); esto es, se trata de describir y comprender lo que hace la gente; observar, escuchar y participar en la vida cotidiana, mas no desde una posición apartada de la comunidad, sino desde adentro en un diálogo mutuo, que no finaliza en el relato. Se realizó observación participante durante nueve salidas de campo, desde abril de 2016 hasta septiembre de $2018,{ }^{8}$ la cual se combinó con conversaciones grupales sobre la familia y con talleres de metodología de investigación de acción participativa con familias campesinas (Cruz et al., 2018); además se georreferenciaron los grupos domésticos; luego, se compararon los resultados de campo con las etnografías realizadas por Boremanse (1978, 1998) y Marion (1999). De los elementos culturales planteados por Bonfil (1991), este artículo se enfoca en los materiales, tierra y casa, así como en las formas de organización social relacionados con ellas, para lo cual se usan las categorías de análisis: residencia, herencia y trabajo.

\footnotetext{
${ }^{8}$ Cada salida de campo incluyó estancias de entre dos y seis semanas.
} 


\section{El vejo'ovex: familia, grupo doméstico y sistema de residencia}

Se ha demostrado que los cambios estructurales provocan cambios en las familias y que los procesos económicos generan cambios en el ámbito de la vida privada (Vera y Socarrás, 2008); como se verá, en Lacanjá Chansayab los cambios en las actividades económicas han repercutido en la vida cotidiana de las familias.

A pesar de que en maya lacandón no existe una palabra equivalente a familia, existe el término vejo'ovex, concepto que nos dieron a conocer durante mayo y junio de 2017 durante la realización de los talleres mencionados (Cruz et al., 2018). Vejo'ovex apareció por primera vez como alternativa para llamar al festival cultural propuesto por la comunidad durante los talleres, sustentado en que además de ser la forma de organización social en la que trabajan, por familias, es también el conglomerado de viviendas y cocinas en que habitan. Luego, durante la actividad “¿Cómo es tu familia?” (Cruz et al., 2018), ocho grupos presentaron mediante un dibujo, entre otros aspectos, la conformación de sus familias, número de miembros, el parentesco, sus valores, quién hace qué con quién, quién ayuda a quién y sus lugares de residencia, y varios de estos grupos denominaron vejo'ovex al dibujo. El vejo'ovex integra los conceptos de familia, grupo de residencia y grupo doméstico; por tanto, comprender el sistema de residencia de los lacandones lleva a discutir algunos de estos conceptos.

Iniciamos con el parentesco, término que de acuerdo con Needham (1971: 3-5), tiene múltiples usos; se refiere a varios elementos que pueden o no estar interconectados entre sí, por lo que propone una división tripartita: clasificación (terminología), comportamiento y reglas. En este artículo abordamos aquellos aspectos del parentesco relacionados con la asignación de derechos y su transmisión de una generación a la siguiente. De los derechos que en este sentido plantea Needham $(1971: 3,11)$, nos centramos en la pertenencia grupal, la sucesión de roles y ocupaciones, la herencia de propiedad o de cualquier otro elemento, la residencia y la formación de grupos de acción (Estrada, 2005: 37).

El grupo doméstico, por su parte, se refiere a una organización estructurada a partir de redes de relaciones sociales establecidas entre un conjunto de personas, unidos o no por lazos de parentesco, que comparten además de un espacio vital, un conjunto de actividades (Bender, 1967; Gil, 2007; Junko, 1979). Estas actividades por lo general están asociadas con la producción y el consumo de alimentos, la reproducción sexual y la crianza de los hijos, por lo cual se le llama doméstico. Es importante aclarar que las relaciones dentro del grupo doméstico involucran no sólo aspectos materiales, sino también afectivos, simbólicos y culturales (De Oliveira y Salles, 1989: 31), por lo cual, aun cuando en cada generación las actividades se adecúan al contexto histórico, guardan relación con los patrones culturales de corresidencia, autoridad entre género y generaciones, deberes y afectos (Gil, 2007: 93).

Es decir, la reproducción de los grupos domésticos va más allá de la sustitución de sus miembros; las actividades que en su ámbito se realizan, además de 
permitir la manutención cotidiana, transmiten de una generación a otra aspectos ideológicos sobre los que las relaciones sociales básicas se fundamentan (De Oliveira y Salles, 1989: 31); De Oliveira y Salles (1989: 31) sostienen que, cuando el grupo doméstico, como en el caso de Lacanjá, se construye sobre las reglas de parentesco y matrimonio, su reproducción implica la recreación de la familia como institución en aspectos referidos a normas, costumbres y prácticas culturales, como la herencia.

Lo anterior lleva a discutir las patrilíneas y matrilíneas, que se refieren a grupos de filiación unilineal, es decir, aquellos cuyos miembros descienden de un antepasado o antepasada común, por línea de varón (patrilineal) o de hembra (matrilineal), y poseen un territorio o cualquier otro patrimonio real o inmaterial, cuya herencia y derechos se reservan a los hijos o hijas de sus miembros (Fox, 1990: 80). En el sistema patrilineal (agnaticio o de línea paterna), la herencia de los derechos territoriales, de las propiedades o títulos, o de cualquier otra cosa, se reserva a los hijos de sus miembros masculinos. Mientras en el matrilineal (de línea materna o uterino) la herencia de los derechos se reserva a los hijos de sus miembros femeninos (Fox, 1990: 80, 91).

Analizar los sistemas patrilineal y matrilineal en el contexto de Lacanjá Chansayab supone añadir el componente de residencia a los grupos de filiación, denominados por Fox (1990: 122) como grupos locales, los cuales se basan en algún tipo de residencia común; aunque existen diferentes tipos, describimos los que se presentan en comunidades lacandonas (Boremanse, 1978; 1998; Marion, 1999). La matrilocal es aquella en que la pareja al casarse convive con la madre de la mujer, es decir vive en el grupo de la esposa (Fox, 1990: 80). En el caso de la patrilocal, luego de casarse la pareja convive con el padre del hombre, viven con el grupo del esposo (Boremanse, 1978: 21; Fox, 1990). De acuerdo con Marion (1999: 86, 94), en Lacanjá Chansayab se trata de un sistema de residencia matrilocal, con una regla de descendencia patrilineal que en el pasado estuvo ligado a los onen. ${ }^{9}$

Como se mencionó, las etnografías de Boremanse $(1978 ; 1988)$ y Marion (1999), coinciden en que en Lacanjá los grupos de residencia son de tipo matrilocal, y agregan que, si bien socialmente las decisiones son tomadas por los hombres de la comunidad, son en realidad las mujeres al interior de las familias quienes las determinan. Lo anterior, de acuerdo con Fox (1990), se trata de una solución matrilocal en la que las hembras están juntas y los varones dispersos, con un tipo de organización que se basa en los papeles de madre-hija-hermana, a quienes corresponde en cierta medida el peso del control y la continuidad del grupo, además con un mayor poder y prestigio de las mujeres, como se afirma que ocurre en Lacanjá (Marion, 1999).

Así, el vejo'ovex, no es sólo la estructura de una familia, un grupo doméstico o de residencia; no se limita a la suma de sus vínculos genealógicos, sino que es la

\footnotetext{
${ }^{9}$ Linajes con nombres de animales (Marion, 1999: 86).
} 
configuración total de las relaciones sociales entre sus miembros, con repercusiones en el territorio, tanto materiales como simbólicas.

\section{Resultados. ¿Qué está pasando con la residencia en Lacanjá Chansayab?}

Los estudios realizados por Boremanse $(1978 ; 1988)$ y Marión (1999), entre los años setenta y noventa del siglo pasado, destacan que el sistema de residencia y patrón de asentamiento de los lacandones - matrilocal en el caso de Lacanjá Chansayab- era una de las características de su cultura que por entonces se conservaba. No obstante, entre las etnografías realizadas y lo observado en campo vemos que la situación ha cambiado; de acuerdo con los resultados obtenidos se puede afirmar que en la actualidad en Lacanjá predomina un sistema ambilocal.

La Figura 2 representa los grupos domésticos en Lacanjá Chansayab, con los ambilocales en gris, los matrilocales en blanco y los patrilocales en negro; se observa cómo el sistema de residencia predominante en todos los grupos y barrios (Lacanjá, Nahá, San Javier, Crucero Bonampak y Betel) es el ambilocal. Vale anotar que, en la actualidad, los límites entre los espacios de los grupos domésticos y a su interior son difusos, además de haber traslapes entre ellos; varios se han fragmentado, lo que imposibilita tener un número exacto de grupos domésticos.

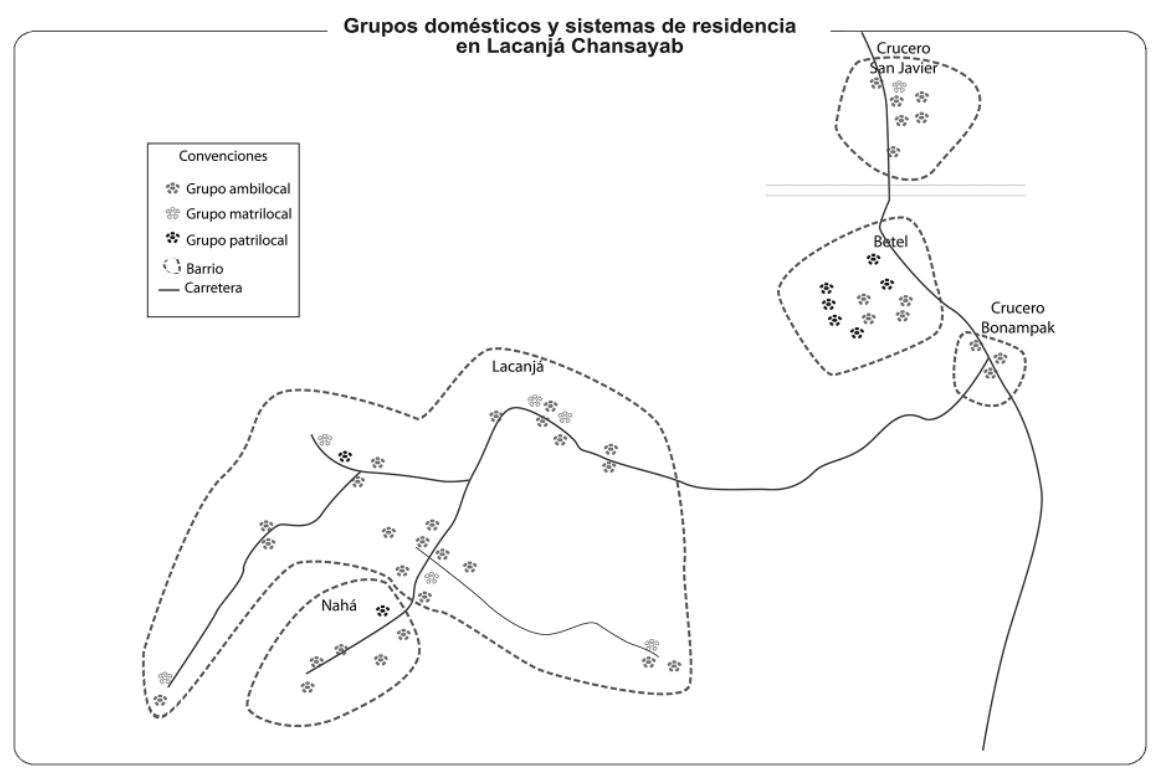

Figura 2. Grupos domésticos y sistemas de residencia (Autoría propia). 
¿Qué pasó en ese tiempo y a qué se debe el cambio? Se identifican tres grandes hechos que detonaron los cambios en el sistema de residencia: la sedentarización y posterior titulación de tierras en los años setenta; la migración de lacandones del norte hacia Lacanjá Chansayab, y con ella las alianzas y matrimonios, y la constitución de empresas familiares para la venta de servicios turísticos a finales de los noventas. Estos tres elementos se encuentran imbricados, y no es posible determinar los límites entre las causas y consecuencias de cada uno, por lo que a continuación se sitúan en un contexto histórico.

\section{Titulación de tierras}

Luego de la sedentarización de los lacandones, y como respuesta a la excesiva deforestación de la selva y a diferentes intentos de colonización, en los años setenta se creó, por parte del gobierno mexicano, la Zona Lacandona, y con ello se otorgaron tierras a los que, para muchos, eran considerados herederos de los mayas auténticos, que estaban acostumbrados a convivir y cuidar de la selva (Boremanse, 1978; De Vos, 1988; Ita, 2018; Trench, 2002).

En 1971 se firmó el decreto con el que se creó la Comunidad Lacandona; en él se le asignaron 614,321 ha de tierra a 66 hombres jefes de familia lacandones, quienes de acuerdo con el decreto vivían en el mismo poblado, a pesar de que en realidad Nahá, Metzabok, Zapote Caribal y Lacanjá Chansayab, se encuentran a casi $100 \mathrm{~km}$ de distancia entre sí (Trench, 2002: 77). Para otorgar la tierra, el gobierno puso, entre otras, dos condiciones: todos los lacandones que aún vivían dispersos en la selva debían concentrarse para vivir de forma permanente en centros poblados (subcomunidades); asimismo, se debía establecer una forma de organización social y de gobierno, el Comisariado de Bienes Comunales de la Zona Lacandona, cuya máxima autoridad por acuerdo firmado con choles y tzeltales en 1977 debía ser un lacandón (Trench, 2002: 77); es decir, se impuso una forma de organización social y de gobierno que no correspondía a su cultura.

En 1975 se extendió la Zona Lacandona a 662,000 ha para incluir a los pueblos del norte, Nahá y Metzabok, convirtiendo a los lacandones en los más grandes propietarios de tierra en la historia moderna de México (Trench, 2002). La tierra y los derechos correspondientes se entregaban en todos los casos a hombres jefes de familia, y no hubo ninguna mujer lacandona, excepto las viudas que obtenían el derecho posterior a la muerte de sus esposos (Nečasová, 2010). Ello bajo unas reglas de herencia patrilineales propias del estado patriarcal, sin importar que, como se anotó, los lacandones del sur fuesen matrilocales.

Entre 1974 y 1976, grupos indígenas tzeltales y choles iniciaron las negociaciones por la titulación de tierras, y en 1979 se expidió el decreto por el que se crearon las comunidades de Nueva Palestina y Frontera Corozal como espacios sociopolíticos importantes (Trench, 2002). Debido, entre otras razones, a 31 ex- 
propiaciones (Secretaría de Desarrollo Agrario, Territorial y Urbano, ${ }^{10} 2019$ ) y a la titulación de tierras en comunidades de otras etnias que han constituido nuevos poblados; durante las cuatro décadas posteriores a la creación de la Zona Lacandona, su superficie continuó reduciéndose y en la actualidad se estima en 446,476 ha (Ita, 2018: 67). La Comunidad Lacandona cuenta con 1,700 comuneros reconocidos (sEDATu, 2019) de las tres etnias que la habitan, en las seis subcomunidades que en la actualidad forman parte de la Autoridad de Bienes Comunales de la Selva Lacandona, distribuidos así: 13\% de comuneros lacandones correspondientes a Lacanjá Chansayab, Nahá, Metzabok y Ojo de Agua Chankín; 51\% de comuneros tzeltales ubicados en Nueva Palestina, y 36\% de comuneros ch'oles habitantes de Frontera Corozal (Ita, 2018: 67).

Otro elemento importante con respecto a la titulación de tierras es la creación de áreas protegidas dentro de la selva. La primera fue la Reserva de la Biósfera Montes Azules ${ }^{11}$ a finales de los años setentas, a la que se sumaron nueve áreas más, al punto de que en la actualidad más del $80 \%$ de la Comunidad Lacandona está bajo alguna categoría de conservación (Ita, 2018: 76). La creación de estas áreas trajo como consecuencia que una institución estatal limite el tipo de actividades que se realicen dentro de ellas, incluyendo la agricultura, la caza y el hábitat de las personas.

De regreso al caso de Lacanjá Chansayab, durante un periodo todos los hijos varones heredaron estatus de comuneros, aunque ahora se ha restringido; por lo general, los títulos se heredan por línea de varón al hijo mayor y a las viudas en el caso de fallecimiento de su esposo lacandón. Aparecen casos en los que los padres le heredan a otro hijo, a un nieto o a una de sus hijas; asimismo, en los que la esposa no es lacandona, una sobrina o una hermana puedan heredar, esto siempre que el titular las nombre como beneficiarias y la comunidad en deliberación apruebe la decisión. En varios de los casos en que una mujer (viuda, hermana, hija) es quien hereda el título de la tierra, debe declarar ante la comunidad que hay un hombre responsable y beneficiario del título.

Vale destacar que la herencia del estatus de comunero (forma de título de la tierra) no equivale a la exclusividad en su uso por parte del "derechoso", ${ }^{12}$ ni a la herencia directa del espacio de residencia. Puede haber diferencia entre quien es el poseedor del título de la tierra y quien hace uso de ella, ya sea para residencia, milpa o actividades de ecoturismo. Así, es común que el grupo de residencia que incluye varias generaciones y familias nucleares esté titulado a uno de sus miembros y en él se sigan construyendo nuevas unidades de residencia, como también lo es que en el terreno titulado a un hombre sean su padre y sus hermanos quienes tienen milpas. Sin embargo, el titular del derecho sí cuenta con mayor poder, debido a que tiene la capacidad de incidir en la toma de decisiones del

${ }^{10}$ En adelante SEDATu.

11 En adelante REBIMA.

${ }^{12}$ Nombre coloquial con el que la comunidad se refiere al comunero o titular de la tierra. 
comisariado y al ser derechoso adquiere beneficios como el recibir una parte del dinero que se le cobra a turistas por entrar a la comunidad, acceder al pago por servicios ambientales o poder construir centros ecoturísticos en su terreno, además de acceder al dinero de indemnización por expropiaciones, entre otros.

\section{Inmigración y alianza matrimonial}

Lo primero a señalar es que la población de Lacanjá Chansayab pasó de 117 personas en 1974 (Boremanse, 1978: 6) a 976 en 2018, ${ }^{13}$ lo que determina una mayor densidad poblacional en un grupo que, como se anotó, hasta mediados del siglo pasado era seminómada y cuyo patrón de asentamiento consistía en vivir en grupos socioparentales distribuidos en la selva y separados entre sí (Boremanse, 1978; Trench, 2002). Dicho aumento en la población se debe a múltiples causas, una de ellas la inmigración. Gracias a las características ecosistémicas de Lacanjá Chansayab, que con respecto a Metzabok y Nahá ofrece mejores condiciones para la agricultura y la caza, sumado a la facilidad de acceso a un área mayor, así como a la evangelización (Boremanse, 1978; Eroza, 2006; Ita, 2018), a partir de los años setenta han migrado a Lacanjá un número importante de lacandones provenientes de esas dos subcomunidades, que como se señaló son ambilocales.

Los originarios de Nahá se ubicaron en el barrio del mismo nombre en Lacanjá Chansayab. Tiempo después, los provenientes de Metzabok formaron el barrio Betel y algunos otros el de San Javier; con un patrón de asentamiento más denso, las viviendas se construyeron más cerca unas de otras y alrededor del templo, en respuesta a las demandas del pastor adventista con el fin de mantener bajo su control a los fieles y permitir la vigilancia mutua de los lacandones (Eroza, 2006; Trench, 2002). Hoy los barrios Nahá, San Javier, Bonampak y Betel representan alrededor del $30 \%{ }^{14}$ de la población total de Lacanjá Chansayab. La migración de lacandones del norte dio como resultado que en el área de Lacanjá Chansayab confluyeran grupos domésticos patrilocales, ambilocales y matrilocales. Durante los primeros años no hubo matrimonios entre miembros de diferentes barrios, lo que permitía que se mantuvieran las reglas de residencia; no obstante, esto cambió de forma paulatina en las últimas décadas.

En la actualidad, hay varias parejas constituidas por miembros de barrios diferentes y con ello las reglas de residencia se han transformado hacia la ambilocalidad. Por ejemplo, un hombre del barrio Lacanjá que se dedica a la guía turística se mudó a la casa de sus suegros en el barrio Betel que era ambilocal. Otro hombre del barrio Lacanjá (matrilocal) al casarse, se fue al grupo de residencia de su suegro en el barrio Nahá (ambilocal).

\footnotetext{
13 Según cifras de La Casa de Salud de la comunidad.

14 De acuerdo con cifras de la Casa de Salud de la comunidad.
} 
Los hombres buscan esposas en otros grupos indígenas y hoy, incluso en pueblos no indígenas. Según cifras de la Casa de Salud de la comunidad, de los 976 habitantes de Lacanjá Chansayab alrededor del $9.7 \%$ son de origen externo, en su mayoría son mujeres tzotziles, choles y tzeltales, que se casaron con un lacandón.

En el pasado, debido a la falta de mujeres y a que el estatus de los hombres estaba asociado a conseguir al menos una esposa, los lacandones enfrentaban conflictos y tensiones que les forzaban a casarse con las de su propia familia o a robarlas de otros grupos familiares; si una mujer enviudaba, era tomada por otro hombre de la familia, sin importar si era más joven o si el hombre ya tenía esposas. Por esta razón se daban casos en los que el hombre se casaba con su suegra o con hermanas de su esposa (Marion, 1999).

Desde la década de los setentas, tanto mujeres como hombres lacandones empezaron a casarse con miembros de otros grupos indígenas de zonas aledañas (Boremanse, 1978, 1998). Mientras las y los jóvenes de forma paulatina comenzaron a rechazar la forma tradicional de selección de las parejas, a cuestionar el poder de los mayores y las obligaciones de servicio nupcial, elementos fundamentales en el sostenimiento del sistema social (Marion, 1999). Con la llegada de mujeres no lacandonas la situación de las locales se hizo más difícil; en la actualidad, debido a las múltiples opciones de conseguir esposa fuera de la comunidad, las viudas y las mujeres separadas se suelen quedar solas (Nečasová, 2010). A diferencia del pasado, hoy la población femenina representa el 50.3\% de la comunidad.

Un aspecto por resaltar es que cuando el esposo es de fuera, la regla de residencia define que la esposa debe irse a la comunidad del esposo; sin embargo, se observa que en los últimos años algunas mujeres, cuyos esposos son foráneos, viven en la subcomunidad. La mayoría regresan a vivir sin su esposo al grupo de residencia de la madre o el padre, siempre y cuando sea comunero. También se han observado varios casos en que, gracias a la lucha de las esposas, se ha logrado que el esposo foráneo viva en la subcomunidad, en el centro ecoturístico en el que trabaja o del que es socio. Asimismo, se dio el caso de una mujer que luego de enviudar se casó con un tzeltal, con quien vive en el mismo espacio de su difunto esposo.

A lo anterior se suma la permanencia de madres solteras en la subcomunidad, en su mayoría jóvenes, algo que hasta hace poco más de 20 años no se permitía; en 2018 sumaban alrededor de $36 .{ }^{16}$ La mayoría de parejas de las madres solteras no son lacandones; el grupo doméstico del padre alberga a estas mujeres con sus hijos, quienes serán lacandones por crecer bajo la tutela del grupo, manteniendo el prestigio de la etnia y la familia. Esto en consonancia con lo

\footnotetext{
${ }^{15}$ Según cifras de La Casa de Salud de la comunidad.

${ }^{16}$ Según cifras de la Casa de Salud de la comunidad.
} 
planteado por Marion (1999: 94), pues para los hach winik de Lacanjá, la familia ${ }^{17}$ y el $\mathrm{Na}^{18}$ no existen sin la presencia de la mujer, que los dirigen y reproducen. En agosto de 2018 la asamblea de la comunidad tomó la decisión de derogar la prohibición de que las mujeres casadas con foráneos permanecieran en Lacanjá.

Para algunas mujeres casadas con foráneos y en general para miembros de familias en las que predominan personas que no son lacandones, el linaje ya no importa. "Ya que los linajes están rotos, desde los setenta cada quien hace lo que quiere" (Nubia Chankín, ${ }^{19}$ junio de 2017).

Tal afirmación haría pensar que en la actualidad todas las reglas de residencia y herencia están rotas; sin embargo, para la mayoría de los hombres, en especial los mayores y los del barrio Lacanjá, el linaje sigue siendo un aspecto fundamental. Sin importar el tiempo que lleven en la comunidad, a las mujeres de fuera que son casadas con lacandones se les llama "no mayas", y sus nombres son menos recordados que los de las lacandonas por los miembros de la comunidad. Aunque vale la pena señalar que son mujeres foráneas las propietarias de la mayoría de las tiendas de la subcomunidad y que algunas de ellas se han convertido en gestoras de cambios sociales importantes, como la búsqueda y formulación de proyectos y la organización de campañas de salud, educación y formación.

\section{El trabajo y las empresas familiares}

Varios autores coinciden en que los hach winik al vivir dispersos en la selva, a diferencia de otras etnias de Chiapas, no sufrieron la influencia de la Conquista ni de la Colonia española; por esta razón no tuvieron que trabajar en fincas o empresas madereras durante el siglo xIx; además su cristianización se dio más tarde, durante el siglo xx (Boremanse, 1978; Marion, 1999; Nečasová, 2010). Por otro lado, el interés de los lacandones por el comercio con personas externas está documentado desde finales del siglo xvili; se trataba del intercambio de productos de sus milpas por objetos como machetes, telas, sal, entre otros; durante los siglos xix y xx, con el auge de la explotación maderera en la zona y la posterior llegada de los primeros antropólogos, chicleros, misioneros e investigadores, los contactos entre lacandones y foráneos se hicieron cada vez más frecuentes (De Vos, 2002; Nečasová, 2010; Trench, 2002).

Durante el siglo xx los lacandones continuaron con sus actividades tradicionales, la milpa, la caza, la pesca y la recolección de plantas y caracoles de la selva, para autoconsumo familiar, junto con el comercio. A partir de 1974 se empieza a incrementar la llegada de recursos monetarios por extracción de madera, y en

\footnotetext{
${ }^{17}$ En este caso familia nuclear.

18 Hace referencia a madre, mujer y casa (parte inmaterial) (Marion, 1999).

19 Todos los nombres han sido cambiados para proteger su identidad.
} 
la década de 1990 aparecen también proyectos de desarrollo, como la extracción de palma xate y el turismo (Trench, 2002).

Con respecto al turismo, fue a finales de los años cuarenta con el descubrimiento de la zona arqueológica de Bonampak que se detonó el interés en la zona (Semarnat, 2010; Trench, 2002). Durante los primeros años los visitantes eran en su mayoría mochileros tras la aventura de conocer Bonampak y a los lacandones; no existían cabañas, restaurantes o centros turísticos como tales, tan sólo algunos hombres de manera informal ofrecían a los visitantes espacio para acampar y comida. A los turistas no siempre se les cobraba, con un "regalo" bastaba. Trench (2002) afirma que durante la década del noventa se dinamizó el turismo en la zona, gracias a la Cumbre de Río de 1992, la creación de la Ruta Maya y luego el Mundo Maya ${ }^{20}$ y la finalización de la carretera Fronteriza ${ }^{21}$. En Lacanjá, el ecoturismo se llevó a cabo como estrategia de conservación de la selva y sus áreas protegidas, motivado por la construcción de la carretera al sitio arqueológico de Bonampak y el Proyecto de Ecoturismo Bonampak financiado por la Comisión Nacional de Áreas Protegidas, ${ }^{22}$ (en ese entonces Instituto Nacional de Ecología), la Secretaría de Turismo, ${ }^{23}$ el Instituto Nacional Indigenista (INI, hoy Instituto Nacional de los Pueblos Indígenas) y Conservación Internacional en 1997 (Trench, 2002).

En este punto es importante señalar que el turismo como actividad económica requiere de la conformación de empresas y la construcción de infraestructura. En ese sentido, uno de los primeros proyectos fue el Centro de Interpretación Ambiental y Servicios ${ }^{24}$ en la entrada al Monumento Natural Bonampak, ${ }^{25}$ y la conformación de la Cooperativa Jach Winik en la que se vincularon más de 100 personas de diferentes familias de la subcomunidad Lacanjá, incluyendo mujeres y niños; el objeto de la cooperativa era administrar y prestar los servicios de guía turística, transporte y venta de artesanías del CIAS y el MNB (Trench, 2002: 127). Múltiples razones, entre ellas que el proceso no hubiera surgido de la comunidad sino de instituciones externas; el desconocimiento por parte de estas instituciones de principios culturales de las mujeres lacandonas y de sus formas de organización, y la falta de claridad en el manejo de los ingresos y la propiedad de la cooperativa, ligadas a que no se les explicó cómo se administra un negocio, llevaron a que el cias dejara de operar. La experiencia con la Cooperativa Jach Winik es la razón por la que los lacandones rechazan trabajar en forma asociativa.

\footnotetext{
${ }^{20}$ Proyecto turístico de un circuito que conectaba a diversas zonas arqueológicas mayas de Mesoamérica.

${ }^{21}$ Vía que rodea la Selva Lacandona; además de conectar con Guatemala llega muy cerca de Lacanjá Chansayab.

22 En adelante CONANP.

${ }^{23}$ En adelante SECTUR.

24 En adelante CIAS.

25 En adelante MNB.
} 
De manera simultánea algunos miembros de la comunidad conformaron varias cooperativas transportistas formales e informales que impidieron el acceso de cualquier vehículo al $\mathrm{MNB}$, con el fin de manejar de forma exclusiva la transportación (Trench, 2002), y hasta el día de hoy continúan operando así. Luego, en 2002, la organización Espacios Naturales y Desarrollo Sustentable A.C. ${ }^{26}$ (Ingenieria Ambiental del Sureste, 2002; Trench, 2002) aportó recursos para el proyecto de un gran centro ecoturístico, aunque la comunidad no estuvo de acuerdo y pidieron que se distribuyeran los recursos en once campamentos ecoturísticos para un número igual de familias de Lacanjá Chansayab. En el manifiesto de impacto ambiental de dicho proyecto se determinó la ubicación de las cabañas "en los traspatios de las familias de las Subcomunidades Lacandonas de Betel y Lacanjá Chansayab" (Ingenieria Ambiental del Sureste, 2002: 21).

El INPI, SECTUR, CONANP y otras instituciones realizaron más proyectos y con ellos más campamentos ecoturísticos, todos con el mismo esquema, uno para cada familia. A partir de tales proyectos se insertó el ecoturismo como empresa al interior de las familias. Asimismo, esta inversión inicial facilitaría alcanzar años más tarde la rentabilidad económica, que en la actualidad permite a la mayoría mantenerse y dedicarse en exclusivo a dicha actividad, sin necesidad de apoyos financieros externos. Es también con la aparición de estas empresas familiares que el lugar de residencia se traslapa con el lugar de trabajo, debido a que los campamentos ecoturísticos (cabañas y restaurantes) se encuentran en el espacio de los grupos domésticos (Figura 3) y varios de los miembros del grupo familiar participan de la actividad turística.

La Figura 3 presenta un ejemplo de vejo'ovex (ambilocal) en el que hay un centro ecoturístico. Los grupos de cabañas de alojamiento del padre, su hijo e hija (A1, A2 y A3), así como el restaurante (R1), están en medio de las unidades de residencia de los padres (01), de sus hijos con sus parejas $(02,04,08)$, de sus hijas con sus parejas $(03,05,10)$, de su hija madre soltera (06) y de sus nietas madres solteras $(07,09)$. Todos los miembros de este vejo'ovex forman parte de la empresa ecoturística.

En la actualidad, el ecoturismo y sus actividades asociadas son la principal fuente económica y de trabajo en Lacanjá Chansayab, seguida de la elaboración de artesanías también vinculada al turismo. La milpa, aunque importante, se ha reducido de forma considerable, tanto en superficie como en fuente de abasto familiar, ya que la compra de alimentos, incluidas las tortillas, a comunidades aledañas, se ha convertido en una práctica común en la mayoría de las familias. La caza, por su parte, casi ha desaparecido, aunque se mantiene la recolección en la selva de alimentos como cangrejos, caracoles, sapos y materiales para artesanías como semillas y bejucos. Al cambiar el tipo de trabajo, surgen cambios en el sistema de residencia, por ejemplo, en aquellos centros ecoturísticos en que se trata de la segunda generación de miembros de la familia dedicados al turismo

26 En adelante ENDESU. 


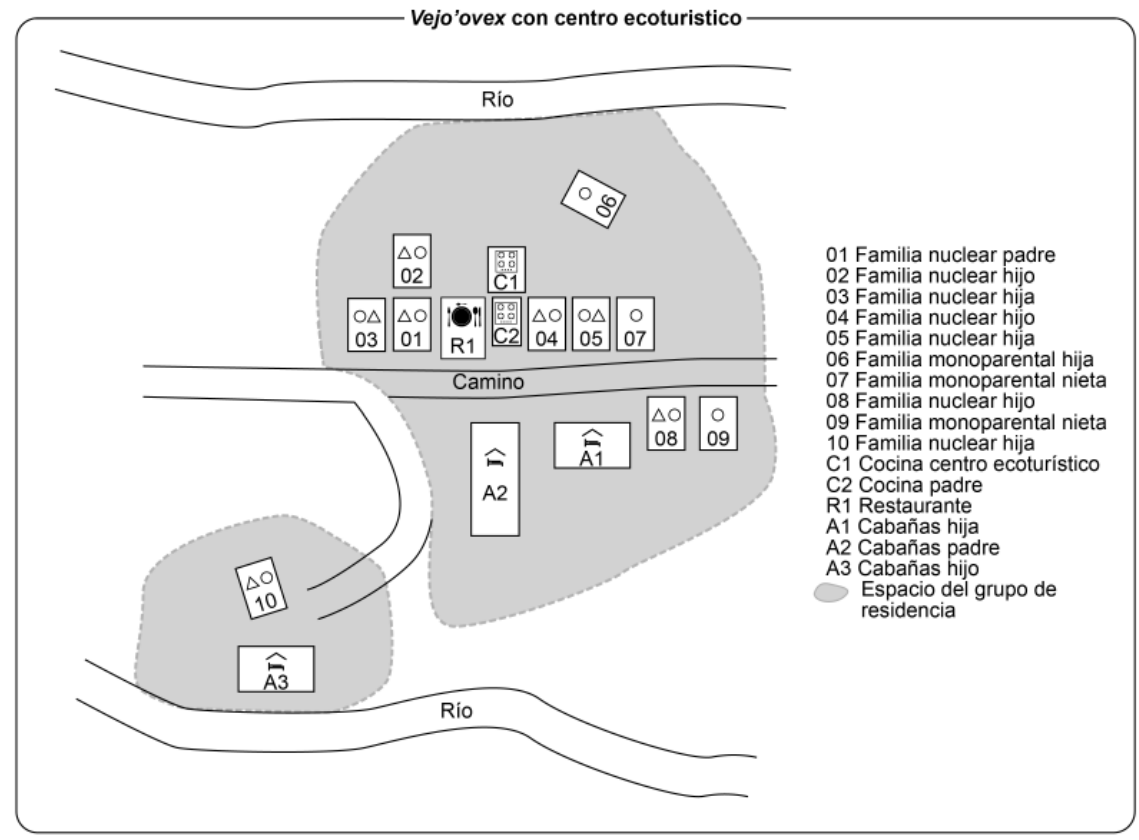

Figura 3. Vejo'ovex en el que hay un centro ecoturístico (Autoría propia).

se observa que, ya sea por decisión del padre o por petición de los hijos hombres, se le entrega la administración a sus hijas si son viudas o separadas, pero en su mayoría a sus hijos, quienes luego construyen sus casas de residencia en el mismo espacio de estos. "El lugar de residencia de una nueva pareja tiene que ver con donde haya trabajo, donde esté el trabajo está la residencia” (Eduardo, 20 de marzo de 2018).

K’in, un lacandón del barrio Lacanjá, se casó con una mujer lacandona del mismo barrio, y afirma que al juntarse con su esposa no pensaron dónde irse a vivir, se fueron a donde sus suegros (es decir, matrilocalidad), pero un año después sí lo hicieron y se mudaron junto a la casa del padre de K’in, debido a que allá había unas cabañas ecoturísticas que desde ese momento empezó a administrar con su esposa. Otro ejemplo en que el trabajo define la residencia es el de un hombre foráneo, pareja de una mujer lacandona, que ahora vive en el barrio San Javier gracias a que junto con su esposa montaron un centro ecoturístico en terrenos del cuñado lacandón. Este caso es relevante en la medida en que, como se anotó, cuando el esposo no es de la comunidad debe irse con su esposa a su lugar de origen; en la comunidad no podían vivir hombres foráneos; la regla está cambiando. Hay también varios casos en que la empleada foránea de un centro ecoturístico se convierte en esposa del administrador que es lacandón, y se va a vivir a la casa de su esposo que está en el espacio del centro. 


\section{Discusión}

Lo expuesto hasta ahora da cuenta de que el sistema de residencia de Lacanjá Chansayab, señalado por Marion $(1999)$ y Boremanse $(1978 ; 1998)$ como matrilocal, ha cambiado en las últimas cuatro décadas hacia lo que de acuerdo con Fox (1990) es un sistema ambilocal. Si bien este cambio es importante no sólo por lo acelerado del mismo y por tratarse de un sistema poco frecuente, vale la pena preguntarse qué hay detrás y hacia dónde se transita. El propósito ahora es discutir los cambios en el sistema de residencia en el marco de la teoría del control cultural tomando como ejes el territorio, el grupo de residencia, la herencia y el trabajo.

A modo de síntesis, la Figura 4 presenta los elementos culturales analizados en el marco del control cultural. La residencia es un elemento propio de los lacandones, cuyas reglas se ven afectadas por decisiones externas, lo que lleva a que transiten hacia ser una cultura impuesta; situación similar ocurre con la herencia, que es un elemento asociado a la residencia; como veremos, si las normas de residencia cambian, las de herencia también, a lo que se suma que las decisiones sobre ella se ven afectadas por otras culturas, por lo que transita hacia una cultura enajenada. El territorio, en este caso la selva, es un elemento cultural de los lacandones; sin embargo, en términos de relaciones de poder, se lo han apropiado los hach winik. El trabajo se ha convertido en enajenación cultural y, finalmente, el ecoturismo es un elemento ajeno a la cultura que además fue impuesto y, no obstante, ha sido adoptado por los lacandones.

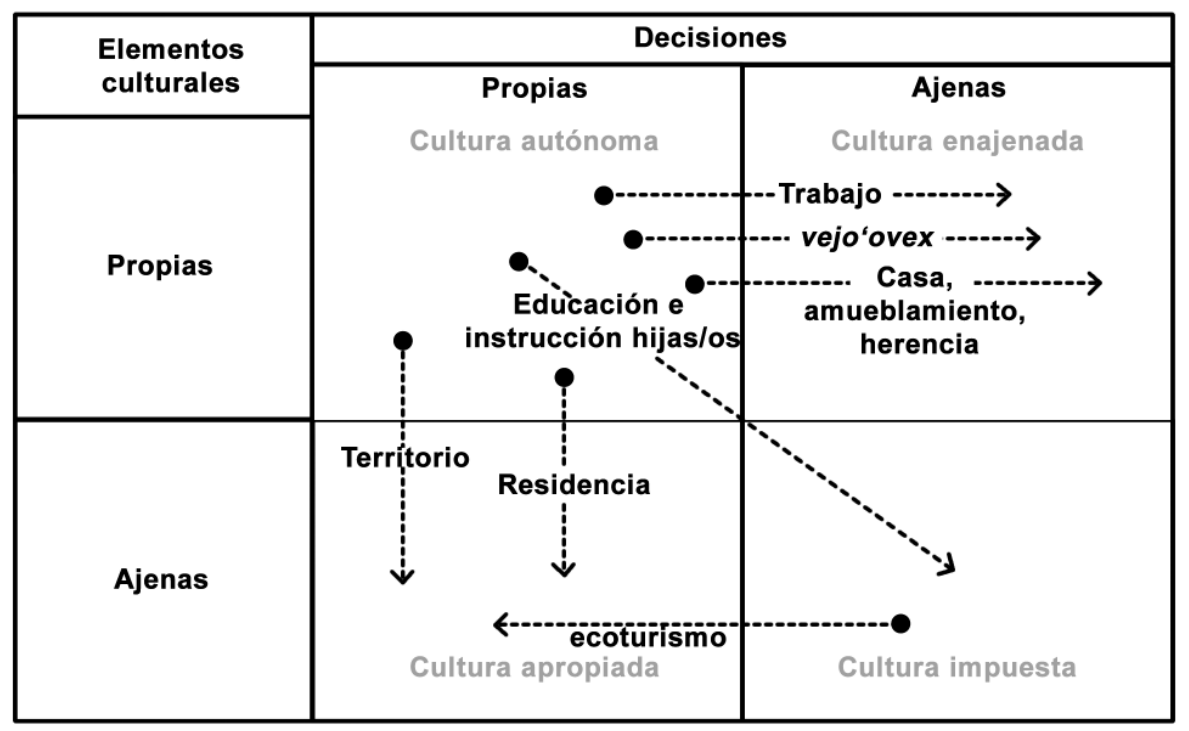

Figura 4. Elementos del control cultural (Autoría propia, a partir de Bonfil, 1991). 


\section{Territorio}

Los lacandones no hablan de territorio sino de la selva, lo que Haesbaert (2011: $35,287)$ denominaría un territorio simbólico cultural. La selva es elemento fundamental de su cosmogonía; es su hogar ampliado, dentro del cual, en una escala menor, el vejo'ovex ocupa un espacio. Como ya se comentó, además de considerarse sus guardianes, en ella se origina, entre otros elementos de su cultura, el sistema de residencia de los hach winik.

Al ser seminómadas, la dimensión material de su territorio variaba en el tiempo, era un espacio dinámico (Haesbaert, 2013: 282). Con la milpa itinerante, el hogar y la residencia se movían; su espacio se construía mientras se vivía como la selva se construye, porque la selva no es un espacio inhóspito a consecuencia de siglos de ausencia humana, es el resultado de procesos antrópicos tales como la milpa tradicional de los mayas antiguos y de los hach winik (Ford y Nigh, 2015). Antes de la sedentarización, existía un territorio construido por los lacandones; estaban en la condición de cultura autónoma (Bonfil, 1991).

Si un grupo es seminómada, con agricultura itinerante, sus formas de organización social, de propiedad y herencia, al igual que su arquitectura y mobiliario, no pueden ser las mismas que las de un grupo sedentario. De allí que la sedentarización de los hach winik y la posterior titulación de sus tierras llevaran consigo cambios sobre la noción de territorio. En primer lugar, se perdió la categoría de espacio dinámico; fueron conminados a permanecer en poblados. Luego, la titulación implicó definir límites y conmensurar un área, términos que para ese momento eran ajenos a la cultura lacandona. Ello a su vez suscitó cambios en los conceptos de propiedad y con ello de herencia.

Aunado a lo anterior, al imponerles una nueva forma de organización de tipo comunitaria con un líder, ajena a su forma de grupos de residencia, cuya autoridad era el hombre mayor, también se generaron cambios en las relaciones de poder sobre la selva. En este punto nos remitimos a Haesbaert $(2011 ; 2013)$, para quien el territorio debe ser concebido como las relaciones de poder construidas en y con el espacio, resultado de la dinámica de desterritorialización y de reterritorialización. Haesbaert (2011: 35-36; 2013), entiende el territorio en un sentido relacional, en el cual el poder no es una capacidad o un objeto que se puede poseer, es más bien una relación de fuerzas desigual. Desde esta perspectiva, el poder se liga muy bien con el control cultural de Bonfil, pues es visto, desde el sentido de la dominación político-económica, como dominación funcional, mientras que desde el sentido simbólico es visto como apropiación cultural (Haesbaert, 2013). Las relaciones de poder dentro de la selva como territorio se extienden ahora no sólo entre los hach winik, sino también con los demás pueblos que forman parte de la comunidad Lacandona y de las diferentes instituciones con injerencia en ella.

Bajo esta perspectiva, la sedentarización de los lacandones fue un paso en la negociación de relaciones de poder entre el estado y el grupo. De un lado, en la escala más pequeña de su territorio, la del vejo'ovex, el espacio de la familia es 
ahora estático. Por el otro, la posterior titulación de las tierras amplía la escala de tales relaciones; les concede poder sobre su territorio debido a que les otorga el liderazgo político y económico de la Autoridad de Bienes Comunales, y se les nombra sus guardianes, lo que representa un poder simbólico. Se trata de otro ejercicio en el que el estado, además de delimitar la selva, les restringe el tipo de actividades sobre ella, les prohibe abrir nuevas áreas para la milpa y la caza, define zonas que no se pueden tocar, todo debido a la creación de la REBIMA y demás áreas protegidas, a lo que los lacandones responden.

Como resultado del otorgamiento parcial de poder, en una escala amplia, los lacandones se apropian de este nuevo concepto de territorio; la selva además de su hogar ampliado es ahora también su territorio económico y político; empiezan a ejercer su poder como "dueños" de la Comunidad Lacandona; se convierten en aliados de organismos e instituciones del estado con el fin de conservar la selva, expulsar a los invasores y aceptar o rechazar proyectos productivos en la misma; asimismo se rehúsan a la ganadería y la palma africana, mientras admiten el pago por servicios ambientales y el ecoturismo.

Muestra de ello es la expulsión violenta, por parte de los lacandones en los años ochenta, de tzeltales que estaban instalados cerca de Lacanjá Chansayab, y la posterior creación del barrio San Javier como mecanismo de defensa y consolidación de su poder sobre la comunidad lacandona (Trench, 2002). Ejemplo del poder simbólico de cómo la imagen de los lacandones — hombres de pelo largo y túnica blanca- es ahora usada en material promocional como representación de la selva conservada, del turismo en la selva y del pago por servicios ambientales. "El gobierno dice lacandón, te quiero, mentira quiere su imagen [...] Soy mal lacandón, no me visto como tal" (Ricardo, septiembre de 2016). Sin embargo, el dinamismo característico tanto del sistema de control cultural de Bonfil (1991) como el de las relaciones de poder de Haesbaert (2011) nos permite ver que esa apropiación cultural del concepto de territorio y ese poder sobre la selva de los lacandones es apenas una señal momentánea de un proceso, en el que por ahora los hach winik dejaron de ser "los consentidos" del gobierno por enfrentársele (Ita, 2018), así como a otras comunidades indígenas y operadores turísticos, por el manejo, conservación y autonomía de "su" territorio.

A cada rato vienen las secretarías, la conANP, todos esos funcionarios de gobierno, ellos nos quieren quitar la selva, para venderla y explotarla, pero la selva es nuestra, nosotros aprendimos de nuestros padres a cuidarla [...] a cada rato los vecinos se meten y cazan, y tumban, ellos no saben cuidar la selva, nosotros los lacandones sí (Domingo, junio de 2017).

\section{El vejo'ovex}

Los resultados de campo muestran que las implicaciones del sistema matrilocal van más allá de la residencia y las formas de herencia del patrimonio. En Lacanjá 
la forma de organización del grupo de residencia tiene que ver con su reproducción social y cultural.

Como se mencionó, el vejo'ovex no es sólo un tipo de organización con fines productivos, es ante todo el espacio inicial donde sus miembros socializan y, por ende, el primer lugar en el cual se transmiten los sistemas de normas y valores que rigen a los individuos y a la sociedad. Es, por tanto, un espacio de aprendizaje, que, en el caso de los lacandones, es el núcleo de la casa ampliada, la selva. Era al interior del vejo'ovex, en las casas, donde niños, niñas y jóvenes aprendían de sus abuelos sobre el vika kaj tar, ${ }^{27}$ que quiere decir la forma de vivir, esto es, el saber hacer la milpa, cazar, construir la casa, elaborar los objetos de uso cotidiano y preparar los alimentos, así como la relación con la selva, los cuentos y las historias.

Antes aprendíamos con los abuelos, en su casa, sobre la milpa y la selva [...] Uff aquí [en el centro ecoturístico] de mi tío, hemos trabajado casi todos, mis primas, mis primos, mis hermanas, mis tíos y yo, yo soy guía [...] Uno aprende a trabajar en la familia (Nubia Chankín, julio de 2018).

En este punto, en correspondencia con lo que plantea Bonfil (1991) sobre la pérdida de la capacidad de decisión del grupo de residencia en aspectos como la instrucción a los hijos, se observa que la escuela reemplazó a la casa ampliada como el espacio de formación para la vida, mientras que los centros ecoturísticos, los restaurantes, los autos, los senderos, son ahora los espacios en que padres y madres forman para el trabajo a hijos e hijas. En este caso observamos una cultura impuesta; el grupo ha perdido el control sobre la educación de sus hijos, tanto en lo material como en lo intangible.

La sedentarización y el ideario del desarrollo tuvieron también otro efecto en la parte material del vejo'ovex. La arquitectura de las casas y el mobiliario efímeros, es decir, muros de madera, techos de palma, muebles y bolsas de material vegetal que se guindan y se transportan, o el comer en el suelo, han desaparecido en forma paulatina. Hoy aproximadamente un $30 \%$ de las casas son de bloques, columnas de cemento, y la mayoría tienen techo de lámina y piso de cemento; todas las familias usan muebles; se prefieren estos materiales y arquitectura sobre los del pasado.

\footnotetext{
${ }^{27}$ El vika kaj tar, nos respondieron en una de las charlas grupales y en dos entrevistas al preguntar qué es ser hach winik, además de hablar maya lacandón es el saber hacer las cosas, el saber vivir, como lo hacen los y las lacandonas. Complementaron que varias etnias hacen pozol, milpa, cazan, cocinan y se relacionan con la selva, pero el vika kaj tar es la forma en que ellos y ellas saben vivir, y los hace hach winik. Al respecto, también se puede ver Chambor y Jiménez, 2018: 58. El vika kaj tar se relaciona con el meek'chähäl, un rito de paso similar al bautismo, en el que cada familia le muestra a los niños y niñas sus deberes en la vida como lacandones; a las niñas se les enseña cómo hacer tortillas, pozol, lavar la ropa, tejer, etc., y a los niños cómo usar un machete, un hacha, la milpa, etcétera (Baer y Baer, 2018: 154; Boremanse, 1978: 127-130).
} 
Muchos dicen que les gustaría vivir y conocer los lacandones de los 60 y 70. Pero hemos cambiado mucho [...] los lacandones comían en el suelo, en la tierra, servían en la tierra, no tenían muebles [...] Se ha perdido gran parte de las tradiciones de los lacandones, por la civilización y la modernidad, yo creo que eso es imparable (K'in, 3 de septiembre de 2016).

El cambio no es menos relevante, pues el saber construir la casa definía el momento en que un hombre podía conseguir esposa para formar familia (Boremanse, 1978), así como el saber elaborar bolsas, mochilas o hamacas era un conocimiento que se transmitía entre madres e hijas. Ello es más importante aún si consideramos que lo que se heredaba no era la propiedad sobre la tierra ni las casas, debido a que éstas se dejaban después de un tiempo, sino que se heredaba el vika kaj tar.

Si la casa y los muebles dejan de ser efímeros, si el espacio que ocupan deja de ser dinámico, ahora pueden ser heredados, lo que se dio con el esquema de titulación de tierras de los años setenta, logrando un efecto similar al del reparto agrario posrevolucionario en México que reforzó la herencia de la tierra con predominio masculino y patrilineal (Arias, 2013). Esto se potenció con la llegada del ecoturismo; ahora las cabañas y centros ecoturísticos son parte de lo que se hereda, aunque es de resaltar que hay varios casos en que las mujeres son las herederas. La casa, el mobiliario y la herencia transitan hacia la enajenación cultural.

Aun cuando quienes llevan el desarrollo y los proyectos productivos tienen una idea diferente de familia ligada sólo al parentesco nuclear, la investigación muestra que el vejo'ovex como organización de trabajo se mantiene; sin embargo, su concepción es diferente en escala y morfología. Por un lado, como mencionamos, ahora los espacios de los grupos domésticos son difusos, hay traslapes y se han fragmentado. Por el otro, se ha observado cómo en los vejo'ovex, cuyo líder es un hombre mayor, se identifican más de 60 miembros de tres o cuatro generaciones como su familia, mientras en los más jóvenes que se dedican de forma exclusiva al ecoturismo lo identificado corresponde a una familia nuclear. El concepto de familia, el vejo'ovex aunque más lejano, también se dirige hacia la enajenación cultural.

\section{El trabajo}

En los resultados se observa cómo el trabajo es una determinante del lugar de residencia, por lo que un cambio en la actividad laboral, como fue la llegada del ecoturismo, redundó en el sistema de residencia. Ahora se discute este aspecto en el marco del control cultural. El ecoturismo como cualquier tipo de turismo, es una actividad exógena que no existía en varias culturas, en especial las indígenas (Ochoa, James y Márquez, 2013: 26); además, al ser un servicio, tiene 
notables diferencias con las actividades productivas a las que pueblos campesinos e indígenas están acostumbrados. El ecoturismo era ajeno a la cultura lacandona, sin embargo, lo aceptaron y hoy, además de ser el sector económico más importante de Lacanjá, goza de reconocimiento en la prestación de estos servicios tanto institucional como por parte de los turistas.

Como se señaló, uno de los primeros proyectos ecoturísticos que se les llevó impuso una forma de organización empresarial de tipo cooperativa con miembros de varias familias, la cual no correspondía con su modo de organización social, lo cual fue una de las razones para su fracaso. Frente a lo anterior, la comunidad propone que la escala de las organizaciones a apoyar sea la del vejo'ovex, que corresponde a su cultura, su forma de reproducción social y sus formas de relacionarse dentro y fuera del grupo de residencia, debido a que como ya se mencionó, aparte de la residencia, el vejo'ovex corresponde también al grupo doméstico y con ello al trabajo de la milpa, la caza, la preparación de alimentos, etcétera.

En la actualidad, no sólo se siembra menos milpa, sino que se hace más cerca al vejo'ovex; casi no se caza; ahora el trabajo está en los centros ecoturísticos, que como anotamos se traslapan con el lugar de residencia. Observamos entonces cómo las reglas de residencia en este caso cambian en función del tipo de trabajo; si se puede realizar lejos del vejo'ovex no incide en la toma de decisión sobre la residencia; ejemplo de esto son los hombres guías o transportistas que no necesitan vivir cerca. Por el contrario, las actividades de cocina y administración de los centros sí requieren vivir cerca, por lo que ya sean hombres o mujeres, una vez que se casan se mudarán al grupo de residencia donde trabajen.

La llegada de las empresas familiares ecoturísticas incide también en las dimensiones física y económica del territorio. Por un lado, los gestores de proyectos, los consultores de planes de negocios y de emprendimiento, ven el valor comercial de los terrenos en los que se encuentran los centros y les asignan un precio con el fin de usarlo como soporte de inversiones o créditos, a pesar de que en la práctica no se puedan comprar. Como mencionamos, independientemente de quién sea el titular de los terrenos donde están los centros o la milpa, los miembros de la familia pueden trabajar y residir en los mismos espacios, y el asignarle un valor monetario al terreno genera suspicacias entre la comunidad. Además, la infraestructura ecoturística es ahora parte de la herencia.

En el marco de análisis de Bonfil, el trabajo es cultura enajenada por los lacandones. Tales cambios afectan las relaciones dentro del vejo'ovex: en varios casos los vínculos familiares se transforman en comerciales y de competencia, con el afán de la ganancia y la rentabilidad. Muestra de ello es que, a diferencia de los años noventa en que los lacandones no se contrataban entre ellos para la milpa, sino que buscaban jornaleros en comunidades vecinas (Trench, 2002), en la actualidad, a causa de las actividades asociadas al ecoturismo, los lacandones se contratan entre sí, entre miembros del vejo'ovex; incluso los favores de sobrinos y sobrinas son remunerados, debido a que se trata de empresas. 


\section{Conclusiones}

El vejo'ovex, además de ser un elemento fundamental de su cultura, es el núcleo de la reproducción social de los hach winik. En el caso de Lacanjá Chansayab, en menos de cuatro décadas el sistema de residencia ha cambiado de matrilocalidad a ambilocalidad. Identificamos tres generadores de este cambio; la sedentarización a comienzos del siglo xx y posterior titulación de tierras en los años setenta; la migración de lacandones del norte hacia Lacanjá Chansayab, y con ella las alianzas y matrimonios, y la reciente constitución de empresas familiares dedicadas al ecoturismo.

La ambilocalidad será cada vez más frecuente por los factores demográficos, porque su espacio de vida es cada vez más pequeño; porque cada vez más se mueven menos; porque ya no son seminómadas y porque el trabajo así lo demanda. La sedentarización, la titulación de tierras y la llegada del ecoturismo trastocaron el sistema de residencia. Este cambio tiene serias repercusiones; desde la teoría de control cultural encontramos que, para los lacandones, los elementos culturales, territorio, vejo'ovex y trabajo se encuentran en una transición de cultura apropiada a cultura enajenada, a la que se ligan transformaciones en los conceptos de herencia, propiedad y familia.

Con respecto al territorio, como afirma Bonfil Batalla (1990), la democracia como instrumento de control cultural lleva consigo un concepto de territorio y de territorio delimitado que además de ser impuesto, desconoce la historia, la trayectoria y las bases sociales y organizativas de los pueblos indígenas. De allí que Bonfil (1990), plantee la restitución de la territorialidad local y que ésta corresponda con la realidad social y cultural de los pueblos, y sea uno de los primeros pasos para construir el México profundo, el México plural; esta restitución implica un reconocimiento de los pueblos como unidades políticas con poder de decisión, así como el respeto a sus formas de organización social.

El desconocimiento del concepto vejo'ovex por parte de quienes llevan proyectos de desarrollo a los hach winik, y el que este concepto no corresponda con los de grupo de residencia o familia, hacen que los cambios en el sistema de residencia de los lacandones sean subvalorados. Hablamos de un cambio en el que las familias y las relaciones a su interior van a convertirse en empresas con relaciones transaccionales y de competencia. Más aún, si tenemos en cuenta el vejo'ovex como hogar de aprendizaje del vika kaj tar, también la relación con la selva puede verse afectada.

En consonancia con lo anterior, la reproducción de los lacandones no está autocontenida sino que se relaciona con la selva; hay un binomio que está en riesgo; si la cultura cambia, la selva cambia; si se impone una forma de organización social, se afecta la selva y por consiguiente la cultura hach winik. Aunque los lacandones son conscientes de los cambios en las actividades económicas, de la casa como lugar de aprendizaje, de su mobiliario y de algunas prácticas culturales, no prevén ni discuten sus implicaciones. Algunos reconocen que las 
nuevas actividades económicas y el dinero han afectado la forma de relacionarse al interior del vejo'ovex y con otras comunidades. No obstante, aún no observan que se trate de cambios en su núcleo social, que afecten su devenir.

La inserción de la empresa en el corazón del vejo'ovex determina el control cultural enajenado en la medida que lleva las relaciones familiares hacia transacciones económicas, en busca de la rentabilidad y la ganancia. Ello repercute en los conceptos de territorio, del que ahora son dueños, así como en el de herencia y patrimonio que ahora tienen valor de cambio. Se transita hacia ese México imaginario que homogeneiza, en el presente caso, hasta los conceptos de familia, comunidad y territorio.

\section{Agradecimiento}

Un agradecimiento muy especial a las personas y familias de Lacanjá, a Justita, Norma, Kayom, Pablo, Enrique, Top, Koj, Abel, Chan Bor, Elías, Carlín, sin quienes este trabajo no hubiera sido posible.

\section{Bibliografía}

Arias, Patricia

2013 "Migración, economía campesina y ciclo de desarrollo doméstico. Discusiones y estudios recientes”, Estudios Demográficos y Urbanos, 28-1 (82): 93-121. Dol: http://dx.doi.org/10.24201/edu.v28i1.1440.

Baer, Phillip y Mary Baer

2018 Diccionario maya lacandón. México: Instituto Linguístico de Verano, A.C.

Bender, R. Donald

1967 "A Refinement of the Concept of Household: Families, Co-Residence, and Domestic Functions", American Anthropologist, 69: 493-504. Dol: https://doi. org/10.1525/aa.1967.69.5.02a00050.

Bonfil Batalla, Guillermo

1990 México profundo. Una civilización negada. México: Grijalbo.

1991 "La teoría del control cultural en el estudio de procesos étnicos", Estudios sobre las Culturas Contemporaneas, 6 (12): 165-204.

Boremanse, Didier

1978 "The Social Organization of the Lacandon Indians of Mexico. A Comparative Study of Two Maya Forest Peoples”, tesis de doctorado en Antropología. Oxford: Universidad de Oxford.

1998 Hach Winik. The Lacandon Maya of Chiapas, Southern Mexico. Nueva York: Institute for Mesoamerican Studies. 
Chambor, Norma y Pablo Jiménez

2018 "Turismo y la casa lacandona como elemento tangible e intangible de la cultura y el modo de vivir en Lacanjá Chansayab", tesis de licenciatura en Turismo Alternativo. San Cristóbal de Las Casas: Universidad Intercultural de Chiapas.

Cruz, Juana, Erin Estrada, Lorena Soto, Manuel Parra, Luis García, Eduardo Bello, Amayrani Meza y Fredy Ochoa

2018 Familia y vida campesina en la frontera sur: caminos de escucha transdisciplinarios, Juana Cruz (ed.). México: El Colegio de la Frontera Sur, Universidad de Chapingo.

De Oliveira, Orlandina y Vania Salles

1989 “Introducción”, Grupos domésticos y reproducción cotidiana, pp. 11-36, Orlandina de Oliveira, Marielle Pepin y Vania Salles (eds.). México: El Colegio de México.

De Vos, Jan

1988 Viajes al desierto de la soledad. Cuando la selva lacandona aún era selva. México: Centro de Investigaciones y Estudios Superiores en Antropología Social.

2002 Una tierra para sembrar sueños. Historia reciente de la Selva Lacandona, 19502000. México: Fondo de Cultura Económica.

Eroza Solana, José

2006 Lacandones: pueblos indígenas del México contemporáneo. México: Comisión Nacional para el Desarrollo de los Pueblos Indígenas.

Estrada, Erin

2005 "Grupo doméstico y usos del parentesco entre los mayas macehuales del centro de Quintana Roo: el caso del ejido Xhazil y Anexos”, tesis de doctorado en Antropología Social. México: Universidad Iberoamericana.

Ford, Anabel y Ronald Nigh

2015 The Maya Forest Garden. Eight Millennia of Sustainable Cultivation of the Tropical Woodlands. Walnut Creek: Left Coast Press.

Fox, Robin

1990 Sistema de parentesco y matrimonio. $4^{\mathrm{a}}$ ed. Madrid: Alianza Editorial.

Gil Montero, Raquel

2007 “¿Métodos, modelos y sistemas familiares o historia de la familia?", Familia y diversidad en América Latina, pp. 77-101, David Robichaux (ed.). Buenos Aires: Consejo Latinoamericano de Ciencias Sociales. Disponible en: <http://biblioteca.clacso.edu.ar/clacso/gt/20101011111019/david.pdf > [consultado el 17 de septiembre de 2018].

Haesbaert, Rogerio

2011 El mito de la desterritorialización. Del "fin de los territorios" a la multiterritorialidad. México: Siglo XXI Editora Iberoamericana. 
Haesbaert, Rogerio

2013 "Del mito de la desterritorialización a la multiterritorialidad", Cultura y Representaciones Sociales, 8 (15): 9-42.

Hofling, Andrew

2014 Lacandon Maya-Spanish-English Dictionary/Diccionario Maya Lacandón-EspañolInglés. Salt Lake City: University of Utah.

Ingeniería Ambiental del Sureste

2002 Manifiesto de impacto ambiental modalidad particular: Proyecto Turístico Lacanjá Chansayab.

Ingold, Tim

2017

“iSuficiente con la etnografía!”, Revista Colombiana de Antropología, 53 (2): 143-159. Dol: https://doi.org/10.22380/2539472X.120.

Instituto Nacional de los Pueblos Indígenas

2015 Atlas de los pueblos indígenas de México. Estadísticas lacandonas. Disponible en: <http://atlas.cdi.gob.mx/?page_id $=881>$ [consultado el 6 de julio de 2018].

Ita, Ana de

2018

"Lacandones, de hijos predilectos a perseguidos ambientales", El Cotidiano, 207: 63-78.

Junko Yanagisako, Sylvia

1979 "Family and Household : The Analysis of Domestic Groups", Annual Review of Anthropology, 8: 161-205.

Marion, Marie-Odile

1991 Los hombres de la selva. Un estudio de tecnología cultural en el medio selvático. México: Instituto Nacional de Antropología e Historia (Colección Regiones de México).

1999 El poder de las hijas de la luna. Sistema simbólico y organización social de los lacandones. México: Plaza y Valdés.

Nations, James y Ronald Nigh

1980 "The Evolutionary Potential of Lacandon Maya Sustained-Yield Tropical Forest Agriculture”, Journal of Antropological Research, 36 (1): 1-33.

Nečasová, Lucie

2010 "Las mujeres lacandonas: cambios recientes", LiminaR. Estudios Sociales y Humanísticos, VIII (1): 80-103.

Needham, Rodney

1971 "Remarks on the Analisys of Kinship and Marriage", Rethinking Kinship and Marriage, pp. 1-34, Rodney Needham (ed.). Londres: Tavistock Publications. 
Ochoa, Fredy, Johanie James y Germán Márquez

2013 "Visión comunitaria de los beneficios derivados del ecoturismo en el Parque Nacional Natural Amacayacu (Amazonas, Colombia)", Gestión y Ambiente, 16 (1): $17-32$.

Secretaría de Desarrollo Agrario, Territorial y Urbano

2019 "Registro Agrario Nacional. Padrón e Historial de Núcleos Agrarios", PHINA. Disponible en: <https://phina.ran.gob.mx/consultaPhina.php> [consultado el 1 de julio de 2019].

Secretaría de Medio Ambiente y Recursos Naturales

2010 Programa de conservación y manejo del monumento natural Bonampak. México: Secretaría de Medio Ambiente y Recursos Naturales.

Trench, Tim

2002 "Conservation, Tourism, Heritage. Continuing Interventions in Lacanjá Chansayab, Chiapas, Mexico", tesis de doctorado en Antropología. Manchester: University of Manchester.

Vera Estrada, Ana y Elena Socarrás de la Fuente

2008 “¿Modelos de familia en Cuba? Una aproximacion desde la cultura”, Familias y culturas en el espacio latinoamericano, pp. 63-80, Ana Vera Estrada y David Robichaux (eds.). México: Universidad Iberoamericana.

Fredy Alfonso Ochoa Fonseca. Colombiano. Licenciado en Diseño Industrial por la Universidad Nacional de Colombia, maestro en Medio Ambiente y Desarrollo por la misma universidad y candidato a doctor en Ciencias en Ecología y Desarrollo Sustentable por El Colegio de la Frontera Sur, San Cristóbal de Las Casas, México. Sus principales líneas de investigación son las relaciones sociedadcultura-naturaleza y el turismo sustentable; desarrolla el proyecto "Ecoturismo y la vida cotidiana de las familias en Lacanjá Chansayab". Entre sus publicaciones recientes se encuentran Tejiendo el territorio. Lineamientos para la construcción del turismo desde lo local, "El dogma de la competitividad frente a la utopía de la sustentabilidad: análisis crítico del ethos desarrollista y economicista" y "Manual de senderos de la vida lacandona”, la primera y la última en coautoría.

fredyochoa@gmail.com

Eduardo Bello Baltazar. Mexicano. Ingeniero agrónomo por la Universidad Autónoma Metropolitana, maestro en Ciencias Agrícolas por El Colegio de Posgraduados y doctor en Antropología Social por la Universidad Iberoamericana. Adscrito a El Colegio de la Frontera Sur, San Cristóbal de Las Casas, Chiapas. Su investigación se centra en las implicaciones sociales del manejo de recursos naturales y desarrolla el proyecto "Procesos comunitarios y domésticos en torno al ecoturis- 
mo". Entre sus publicaciones recientes se encuentran "Conflicto territorial, ecoturismo y cacería no regulada: el traslape de territorialidades en el Área Natural Protegida de Balam-Kú", "Metabolismo social y ecoturismo: la problemática de los residuos en isla Holbox, Quintana Roo, México" y "Metabolismo social y ecoturismo: la problemática de los residuos en isla Holbox, Quintana Roo, México", todas en coautoría.

ebello@ecosur.mx

Erin I. J. Estrada Lugo. Mexicana. Bióloga por la Universidad Nacional Autónoma de México, maestra en Ciencias Agrícolas por El Colegio de Posgraduados y doctora en Antropología Social por la Universidad Iberoamericana. Adscrita a El Colegio de la Frontera Sur, unidad San Cristóbal de Las Casas, Chiapas. Su investigación se centra en la organización social y la apropiación del territorio en el uso de los recursos naturales; desarrolla el proyecto "Estrategias alimentarias en las sociedades indígenas y campesinas". Entre sus publicaciones recientes se encuentran "Cómo es mi familia", "Alimentación cotidiana y organización de los grupos domésticos de la comunidad de Pathuitz, municipio de Chilón, Chiapas" y "Cafetales, agricultura familiar y trabajos en Tenejapa, Chiapas: apuntes desde la perspectiva de género", todas en coautoría.

eestrada@ecosur.mx

Carla Beatriz Zamora Lomelí. Mexicana. Licenciada en Sociología por la Universidad Autónoma Metropolitana, maestra en Estudios Regionales por el Instituto Mora y doctora en Ciencia Social por El Colegio de México. Es investigadora de El Colegio de la Frontera Sur, unidad San Cristóbal de Las Casas, Chiapas. Sus investigaciones se centran en las dinámicas socioterritoriales, la acción colectiva y los procesos organizativos; desarrolla el proyecto "Impacto de las organizaciones cafetaleras sobre el desarrollo local en Chiapas y Guatemala". Entre sus publicaciones recientes se encuentran "Permanencias, resistencias y luchas por la vida", "Campesinos a contracorriente. Estrategias organizativas, productivas y comerciales de la cooperativa indígena campesina Maya Vinic" y "Agroecology and La Via Campesina I. The Symbolic and Material Construction of Agroecology through the Dispositive of 'Peasant-to-Peasant' Processes”, todas en coautoría.

czamora@ecosur.mx

Gloria Mariel Suárez Gutiérrez. Mexicana. Licenciada en Gestión Turística por la Universidad Autónoma de Chiapas, maestra en Ciencias en Recursos Naturales 
y Desarrollo Rural por El Colegio de la Frontera Sur y candidata a doctora en Ciencias en Ecología y Desarrollo Sustentable por el mismo colegio. Adscrita a El Colegio de la Frontera Sur, unidad San Cristóbal de Las Casas, Chiapas. Su investigación se centra en la planificación turística, el ecoturismo y el género; desarrolla el proyecto "El ecoturismo: sus implicaciones y relaciones de género". Entre sus publicaciones recientes se encuentran "Buenas Prácticas en la actividad agroecoturística" en Caminando se aprende: Juntando nuestros saberes para la diversificación productiva, "Integración de una red de agroecoturismo en México y Guatemala como alternativa de desarrollo local" y "Ecoturismo y el trabajo invisibilizado de las mujeres en la Selva Lacandona, Chiapas, México”, todas en coautoría.

gsuarez@ecosur.edu.mx 